\title{
A ORIENTAÇÃO SOCIAL-POLÍTICA DA PALAVRA: REFLEXÕES SOBRE A ESCOLA SEM PARTIDO
}

\author{
José Veranildo Lopes da Costa Junior ${ }^{1}$ \\ Maria do Socorro Maia Fernandes Barbosa ${ }^{2}$
}

\begin{abstract}
RESUMO: Este artigo propõe uma revisão teórica sobre a orientação social-política da palavra, partindo da tese de que nenhum discurso é neutro (BAKHTIN, 1995) e que, portanto, todo discurso é social-político e ideologicamente localizado. Para tanto, nos ancoramos em dois textos fundamentais para os estudos linguísticos e discursivos: Bakhtin (1995) e Volochínov (2013), para traçar um paralelo comparativo sobre o modo pelo qual estes dois autores concebem a orientação social-política da palavra. Para fins de aplicação analítica, buscamos aproximar esta revisão teórica do projeto Escola sem Partido, proposta de natureza política que busca limitar a liberdade de ensinar, e obstruir o pensamento crítico e reflexivo. Como resultado de nossas análises, enfatizamos que: a) Bakhtin (1995) e Volochínov (2013) concebem a linguagem como signo ideológico, ou seja, é na palavra que exprimimos as nossas vivências e o modo pelo qual lemos o mundo e b) sinalizamos para a incoerência do Escola sem Partido pela inexistência de um discurso neutro, pois o próprio projeto em questão é um exemplo ideológico e político de como os professores devem se portar em sala de aula. Por fim, como conclusões, argumentamos que o Escola sem Partido é um projeto político, dado que nenhum discurso é neutro e que os princí́ios propagados por este movimento ferem a autonomia docente e criminalizam o pensamento reflexivo e crítico em sala de aula.
\end{abstract}

PALAVRAS-CHAVE: Discurso. Política. Escola sem Partido.

\section{INTRODUÇÃO}

Nas bases da análise do discurso de linha francesa e dos estudos linguísticos, Mikhail Bakhtin no seu tão conhecido Marxismo e Filosofia da Linguagem, originalmente publicado em 1929, na Rússia, sob os ecos da "grande crise", já argumentava que nenhum discurso é neutro, porque todo discurso é carregado por nossa orientação ideológica e permeado pelos nossos paradigmas de leitura do mundo. Outros autores, reconhecidos pelas suas contribuições para os estudos discursivos, entre eles, Valentin Nikolaievich Volochínov (2013), que também aponta para a orientação ideológica da linguagem, o que pode ser lido, com outras palavras, como a inexistência de um discurso neutro.

Contudo, setores ultraconservadores da elite brasileira parecem negar as contribuições oriundas da filosofia da linguagem, mostrando-se ávidos desconhecedores das bases da análise do discurso, ao propor, dentre outros projetos, o polêmico Escola sem Partido (doravante EsP). Em nossa dissertação

\footnotetext{
${ }^{1}$ Doutorando em Letras pela Universidade do Estado do Rio Grande do Norte - UERN. E-mail: jveranildo@hotmail.com

${ }_{2}^{2}$ Doutora em Estudos da Linguagem pela Universidade Federal do Rio Grande do Norte e Docente do Programa de Pós-Graduação em Letras da Universidade do Estado do Rio Grande do Norte.
} 
de mestrado (COSTA JUNIOR, 2017), afirmamos que o EsP é um projeto político proposto por uma direita ultraconservadora que avança na América Latina, promovendo pautas antidemocráticas, tais como o referido projeto em questão. Para além desta breve explicação, o Escola sem Partido busca limitar a liberdade de ensinar, e, por conseguinte, criminalizar o pensamento reflexivo em sala de aula.

Neste artigo, buscamos revisar dois textos fundamentais (BAKHTIN, 1995 e VOLOCHÍNOV, 2013), para traçar um paralelo comparativo sobre o modo pelo qual os dois autores concebem a orientação discursiva da linguagem. $O$ nosso foco é verificar a concepção de orientação discursiva de ambos os autores, com o objetivo de ilustrar que todo discurso é social-histórico-político e ideologicamente localizado a partir do modo pelo qual o emissor concebe o mundo.

Metodologicamente, nosso artigo encontra-se dividido em cinco tópicos, além destas palavras introdutórias e das respectivas referências bibliográficas. Em Revisitando a noção de palavra para Bakhtin, discorremos sobre o caráter social-político do discurso; na segunda seção, intitulada Volochínov: revisando a função social da palavra, nos interessa argumentar que toda palavra possui uma função social. Posteriormente, em Intersecções entre Bakhtin e Volochínov, apresentamos alguns pontos de confluência entre as contribuições teóricas destes dois autores para pensar na orientação social-política do discurso; em Reflexões sobre a Escola sem Partido, argumentamos sobre a inconsistência teórica deste projeto à luz dos estudos de Bakhtin e Volochínov e, por fim, apresentamos Algumas palavras não conclusivas, momento no qual finalizamos 0 nosso texto.

\section{REVISITANDO A NOÇÃO DE PALAVRA PARA BAKHTIN}

Em Marxismo e Filosofia da Linguagem (1995) Bakhtin sintetiza que os problemas da filosofia da linguagem são pertinentes para o marxismo, porque as bases da teoria marxista estão relacionadas diretamente com o campo da filosofia da linguagem. Nesse sentido, o autor afirma que:

Um produto ideológico faz parte de uma realidade (natural ou social) como todo corpo físico, instrumento de produção ou produto de 
consumo; mas, ao contrário destes, ele também reflete e refrata uma outra realidade que the é exterior. Tudo que é ideológico possui um significado e remete a algo situado fora de si mesmo. Em outros termos, tudo que é ideológico é um signo. Sem signo não existe ideologia. (BAKHTIN, 1995, p. 31).

O filósofo russo é assertivo ao mostrar que os signos fazem parte de uma realidade social determinada, e dessa forma, refletem e refratam outras realidades oriundas do mundo exterior. Para o autor, tudo que é ideológico é um signo e sem signo não existiria ideologia, o que comprova, então, a indissociabilidade entre signo e ideologia e, por conseguinte, a coexistência de um signo neutro - desprovido de ideologia. Bakhtin (1995, p. 31) também sustenta a ideia de que "um instrumento não possui um sentido preciso, mas apenas uma função: desempenhar este ou aquele papel na produção. E ele desempenha sem refletir ou sem representar alguma outra coisa". Como exemplo de instrumentos e sua relação com a realidade social, Bakhtin (1995, p. 32) ilustra:

\begin{abstract}
Um instrumento pode ser convertido em signo ideológico: é o caso, por exemplo, da foice e do martelo como emblema da União Soviética. A foice e o martelo possuem, aqui, um sentido puramente ideológico. Todo instrumento de produção, pode, da mesma forma, se revestir de um sentido ideológico: os instrumentos utilizados pelo homem pré-histórico eram cobertos de representações simbólicas e de ornamentos, isto é, de signos. Nem por isso o instrumento, assim tratado, torna-se ele próprio um signo.
\end{abstract}

Outros exemplos citados, dizem respeito aos produtos de consumo quando transformados em signo ideológico. "O pão e o vinho, por exemplo, tornam-se símbolos religiosos no sacramento cristão da comunhão. Mas o produto de consumo enquanto tal não é, de maneira alguma, um signo" (BAKHTIN, 1995, p. 32). Para o estudioso, um signo reflete e refrata outras realidades, e por isto, todo signo é materializado a partir de determinados critérios de avaliação ideológica. Bakhtin conclui que, "o domínio do ideológico coincide com o domínio dos signos: são mutuamente correspondentes. Ali onde o signo se encontra, encontra-se também o ideológico. Tudo o que é ideológico possui um valor semiótico." (BAKHTIN, 1995, p. 32). Sobre o domínio ideológico de um signo, o estudioso russo explica: ou apreendê-la de um ponto de vista específico, etc. Todo signo está 
sujeito aos critérios de avaliação ideológica (isto é: se é verdadeiro, falso, correto, justificado, bom, etc.). O domínio ideológico coincide com o domínio dos signos: são mutuamente correspondentes. Ali onde o signo se encontra, encontra-se também o ideológico. Tudo que é ideológico possui um valor semiótico. (BAKHTIN, 1995, p. 32).

Se um signo é parte de uma realidade, entende-se que estas realidades são particulares e apresentam diferentes pontos de vista sobre um mesmo objeto ou uma mesma realidade, por exemplo. Nesse horizonte: "cada campo de criatividade ideológica tem seu próprio modo de orientação para a realidade e refrata a realidade à sua própria maneira" (BAKHTIN, 1995, p. 33). Ao tratar do domínio ideológico dos signos, Bakhtin (1995, p. 33) está afirmando que "cada signo é não apenas um reflexo, uma sombra da realidade, mas também um fragmento desta realidade". Dito com outras palavras, um signo é construído por ideologias que são, por sua vez, postas a partir de diversas realidades sociais, o que impossibilita a coexistência de um signo neutro de ideologias. Nas palavras de Bakhtin (1995):

\begin{abstract}
Nesse sentido, a realidade do signo é totalmente objetiva, e, portanto, passível de um estudo metodologicamente unitário e objetivo. Um signo é um fenômeno do mundo exterior. O próprio signo e todos os seus efeitos (todas as ações, reações e os novos signos que ele gera no meio social circundante) aparecem na experiência exterior. Este é um ponto de suma importância. No entanto, por mais elementar e evidente que ele possa parecer, o estudo das ideologias ainda não tirou todas as consequências que dele decorrem. (BAKHTIN, 1995, p, 33).
\end{abstract}

Para Bakhtin (1995) a realidade do signo é objetiva, sendo entendida como um fenômeno do mundo exterior. Para o autor, um signo também se relaciona com a consciência individual do sujeito, e assim, "a consciência só se torna consciência quando se impregna de conteúdo ideológico (semiótico) e, consequentemente, somente no processo de interação verbal" (BAKHTIN, 1995, p. 34). O autor conclui que a consciência ideológica só pode ser explicada a partir de um meio social e ideológico. No eixo central de suas discussões, Bakhtin caracteriza a palavra:

A palavra é o fenômeno ideológico por excelência. A realidade toda da palavra é absorvida por sua função de signo. A palavra não comporta nada que não esteja ligado a essa função, nada que não tenha sido gerada por ela. A palavra é o modo mais puro e sensível da relação social. O valor exemplar, a representatividade da palavra como fenômeno ideológico e a excepcional nitidez de sua estrutura semiótica já deveriam nos fornecer razões suficientes para colocarmos a palavra em primeiro plano no estudo das ideologias. E, precisamente, na palavra 
que melhor se revelam as formas básicas, as formas ideológicas gerais da comunicação verbal. (BAKHTIN, 1995, p. 36).

Portanto, ao nos depararmos com a noção de palavra para Bakhtin (1995) não podemos deixar de considerar que, para este autor, signo, consciência e palavra são construídas a partir da ideologia como marca representativa da materialização do discurso de um sujeito determinado.

\section{VOLOCHÍNOV: REVISITANDO A FUNÇÃO SOCIAL DA PALAVRA}

Antes de revisitarmos as anotações de Volochínov (2013) sobre a função social da palavra, precisamos compreender, ainda que brevemente, o modo pelo qual, para este autor, a enunciação é construída.

Nesta linha de pensamento, a enunciação pressupõe, então, duas faces: a do falante e a do ouvinte, por isto, a enunciação é sempre orientada para um "outro". Para Volochínov (2013), um dos aspectos do intercâmbio comunicativo da comunicação verbal é o social, no qual diversos tipos de enunciação se desenvolvem. Este autor sustenta que, para compreender a construção de uma enunciação, faz-se necessário considerar a situação social que provoca a comunicação verbal, assim: "a essência efetiva da linguagem está representada pelo fato social da interação verbal, que é realizada por uma ou mais enunciações" (VOLOCHÍNOV, 2013, p. 158). Todavia, o autor observa a existência de quatro tipos de intercâmbios comunicativos, sintetizados da seguinte forma:

\begin{tabular}{|l|l|}
\hline \multicolumn{1}{|c|}{$\begin{array}{c}\text { TIPO DE INTERCÂMBIO } \\
\text { COMUNICATIVo }\end{array}$} & LOCAL DE OBSERVAÇÃO \\
\hline $\begin{array}{l}\text { Intercâmbio comunicativo ligado à } \\
\text { produção }\end{array}$ & Fábricas, indústrias, agricultura. \\
\hline $\begin{array}{l}\text { Intercâmbio comunicativo dos } \\
\text { negócios }\end{array}$ & Escritórios e organizações sociais. \\
\hline Intercâmbio comunicativo da vida & Encontros e conversas pela rua, a \\
\hline
\end{tabular}




\begin{tabular}{|l|l|}
\hline cotidiana & conversação cotidiana. \\
\hline $\begin{array}{l}\text { Intercâmbio comunicativo social (no } \\
\text { sentido do próprio termo) }\end{array}$ & $\begin{array}{l}\text { Propagandístico, escolar, científico, } \\
\text { filosófico em todas as suas } \\
\text { variações. }\end{array}$ \\
\hline
\end{tabular}

Quadro 01: elaborada pelos autores com base nos estudos de Volochínov (2013)

De acordo com o quadro 01, o intercâmbio comunicativo social, para Volochínov (2013), pode ser observado não apenas nesse espaço e sim também no âmbito escolar. No sentido próprio do termo, este intercâmbio comunicativo apresenta-se a partir de uma natureza social, construída por falantes. Dito de outra forma, "qualquer situação da vida em que se organize uma enunciação, não obstante, pressupõe inevitavelmente protagonistas, os falantes" (VOLOCHÍNOV, 2013, p. 159). Levando em conta, pois, a presença dos falantes, tem-se a constituição de um auditório da enunciação.

Sobre a enunciação construída em torno do âmbito escolar pelo intercâmbio comunicativo social, deve-se considerar, ainda, que esta enunciação é elaborada por falantes sociais localizados em variantes sociais diversas. É, todavia, fundamental, retomar as palavras do estudioso russo acerca da orientação dialógica da enunciação:

\footnotetext{
"Minha ação será ruim?" "De que ponto de vista?" "Do meu, pessoal?" Mas de onde extraí esse ponto de vista "pessoal" se não dos pontos de vista daqueles com os quais fui educado, junto aos quais estudei, cujas ideias tenho lido nos jornais e tenho escutado em encontros e conferências? E se eu refuto as opiniões do grupo social a que até agora pertencia, é somente porque a ideologia de outro grupo social começou a dominar a minha consciência, preenchendo-a e obrigando-a a reconhecer a exatidão da realidade social objetiva que a gerou. (VOLOCHÍNOV, 2013, p. 165).
}

Além de reafirmar que toda enunciação é dialógica, ou seja, se materializa a partir da relação eu-outro/falante-ouvinte, Volochínov (2013) assegura que os nossos pontos de vista se relacionam com as nossas experiências do mundo e com as nossas vivências sociais, o que elimina, dessa forma, a possibilidade de uma enunciação construída sem as vivências sociais do falante e, certamente, do ouvinte. Destarte, tratando especificamente da orientação social da enunciação, Volochínov (2013) afirma: 
Esta orientação social estará sempre presente em qualquer enunciação do homem, não só verbal, mas também gestual - através de gestos ou mímica - independentemente da forma em que se realiza: tanto se a pessoa fala consigo mesma - monólogo - quanto na conversação participando duas ou mais pessoas - diálogo. A orientação social é uma das forças vivas organizadoras que, junto com a situação da enunciação, constituem não só a forma estilística, mas também a estrutura puramente gramatical da enunciação. (VOLOCHÍNOV, 2013, p. 169).

Dito isto, enfatiza-se que a orientação social estará sempre presente na enunciação do homem (VOLOCHÍNOV, 2013). Este autor, ao observar a realidade, argumenta que existem dois tipos de objetos: os que não possuem significado ideológico, como alguns objetos oriundos da natureza e da vida cotidiana e os objetos que se transformam em signo, obtendo, assim, um caráter ideológico determinado. Utilizando o mesmo exemplo de Bakhtin (1995), Volochínov (2013) ilustra sua argumentação com o objeto foice, que pode ser entendido como um objeto agrícola ou como um símbolo que representa uma posição política específica. Dito com outras palavras, a realidade ideológica apresenta outros significados para objetos da realidade objetiva (VOLOCHíNOV, 2013).

Aproximando-se do eixo central da discussão sobre a orientação social da palavra, Volochínov (2013, p. 193) afirma que um signo pode ser entendido como "objetos materiais isolados", ou seja, um signo refere-se a qualquer objeto da natureza, da técnica ou do consumo que, por sua vez, pode-se tornar signo, desde que adquiram um significado além da sua existência isolada. Dessa forma, Volochínov (2013, p. 193) afirma que "a palavra, por sua própria natureza intrínseca, é desde o início um fenômeno puramente ideológico". Nos seus termos:

Todavia, a palavra, sendo um fenômeno ideológico, é ao mesmo tempo também parte da realidade material. Para dizer a verdade, o material de que é composta é bastante peculiar e não se lhe pode tocar com as mãos, nem provar seu gosto, nem medir com a régua, nem pesar com a balança. Este material é o som que é produzido pelo movimento dos nossos órgãos da fala e que, como sabemos hoje, é regulado pelas leis da realidade material, pelas leis da natureza. (VOLOCHINOV, 2013, p. 194).

Contudo, Volochínov (2013) argumenta que a palavra não se limita à base acústica e fisiológica. É fundamental recordar que as palavras denotam a história social de um povo, e assim: "qualquer signo ideológico, sendo produto da história 
humana, não só reflete, mas inevitavelmente refrata todos os fenômenos da vida social" (VOLOCHÍNOV, 2013, p. 195). Dessa forma, entende-se que as palavras não se limitam a expressar apenas o seu significado material, o seu conteúdo. As palavras acompanham a luta de classes da sociedade, sendo localizadas em períodos e momentos históricos e sociais determinados. Assim:

\begin{abstract}
Recordemos mais uma vez que o falante pertence a uma classe, tem uma profissão, tem certo grau de desenvolvimento cultural. Enfim, ele pronuncia esta palavra (em voz alta ou para si mesmo) numa certa circunstância diante de um ouvinte, presente ou pressuposto. Graças a estas condições, a esta força ("fatores") que organizam tanto o conteúdo quanto a forma da enunciação, as palavras do falante estão sempre embebidas de opiniões, de ideias, de avaliações que, em última análise, são inevitavelmente condicionadas pelas relações de classes. Qualquer palavra, dita ou pensada, exprime um ponto de vista a respeito de vários acontecimentos da realidade objetiva, em diferentes situações. (VOLOCHÍNOV, 2013, p. 196).
\end{abstract}

Ao mencionar que as palavras acompanham uma luta de classe historicamente localizada no mundo social, compreendemos, de acordo com as reflexões postas por Volochínov (2013) que toda palavra refrata um significado ideológico, estando diretamente relacionada com as lutas de classe de determinada sociedade. Para citar um exemplo das lutas de classe materializadas pelas palavras, pensamos nas escolhas lexicais do discurso da grande mídia. Durante o ano de 2016, por exemplo, jovens secundaristas da rede estadual de ensino do estado de São Paulo ocuparam suas escolas em protesto contra os desvios de verbas das merendas. Jornais da grande mídia, sobretudo os pertencentes à Rede Globo de Televisão, noticiaram que as escolas foram invadidas pelos secundaristas. Outros meios de comunicação, vinculados à mídia alternativa, noticiaram que as escolas foram ocupadas pelos secundaristas. ${ }^{3}$

Notem que a escolha lexical dos verbos invadir e ocupar denotam duas faces das lutas de uma sociedade de classes no estado brasileiro. Outro exemplo que nos ajuda a ilustrar esta discussão, também oriundo do discurso da grande mídia, diz respeito ao processo de destituição da presidenta Dilma Rousseff,

\footnotetext{
${ }^{3}$ Fonte 01: Estadão, 10 de abril de 2016: Rio 'importa' invasores de escolas de São Paulo. Disponível em: http://educacao.estadao.com.br/noticias/geral,rio-importa-invasores-de-escolas-desao-paulo,1853824 Acesso em: 09/09/2017.

Fonte 02: Portal G1 Globo/São Paulo, 05 de maior de 2016: Estudantes ocupam Assembleia Legislativa de São Paulo há 36 horas. Disponível em: http://g1.globo.com/saopaulo/noticia/2016/05/estudantes-ocupam-assembleia-legislativa-de-sao-paulo-ha-36-horas.html Acesso em: 09/09/2017.
} 
durante o ano de 2016. Nesse contexto, parte da mídia noticiou que o processo de destituição era um impeachment, enquanto que outros grupos sociais denominaram este processo de golpe 4 . Nos dois exemplos ilustrados em nossa discussão, comprova-se que o léxico utilizado, ou seja, as palavras escolhidas refletem muito mais do que uma mera escolha lexical, mas denotam uma luta de classe simbolizada e amplificada pelas palavras em um contexto social determinado. A ponto de concluir esta reflexão, recorremos às palavras de Volochínov (2013) para quem:

\begin{abstract}
Quando dizíamos que as palavras são verdadeiras ou falsas, parciais ou imparciais, inteligentes ou estúpidas, profundas ou superficiais, não referimos nosso juízo sobre as próprias palavras, mas sobre a realidade objetiva que elas refletem e refratam enquanto palavras-signo. Por este motivo, uma mesma palavra nos lábios de pessoas de classes distintas reflete também pontos de vista distintos, mostra relações diferentes com a mesma realidade, com o mesmo fragmento de realidade que constitui o tema daquela palavra. (VOLOCHínOV, 2013, p. 197).
\end{abstract}

Portanto, fica evidente que a palavra, para Volochínov (2013) é carregada de sentido e significado ideológico, e por sua vez, denota e exemplifica as mais diversas relações com a realidade social. Assim, nossas palavras podem ser entendidas como o nosso juízo de valor sobre o mundo em que nascemos, vivemos e atuamos enquanto seres sociais.

\title{
INTERSECÇÕES ENTRE BAKHTIN E VOLOCHÍNOV
}

Neste momento comparativo entre Bakhtin (1995) e Volochínov (2003) pudemos perceber que, ambos os autores, concebem uma orientação ideológica para a palavra, seja através do signo (BAKHTIN, 1995), seja através da construção enunciativa do discurso (VOLOCHÍNOV, 2003). Os dois autores também ilustram que objetos da realidade social podem se transformar em objetos ideológicos, porque o signo e a palavra denotam uma ideologia

\footnotetext{
${ }^{4}$ Fonte 03: Portal G1 Globo/Portal de notícias, 31 de agosto de 2016: Senado aprova impeachment, Dilma perde mandato e Temer assume. Disponível em: http://g1.globo.com/politica/processo-de-impeachment-de-dilma/noticia/2016/08/senado-aprovaimpeachment-dilma-perde-mandato-e-temer-assume.html Acesso em: 09/09/2017

Fonte 04: Ver o livro Por que gritamos golpe? Para entender o impeachment e a crise política no Brasil (Vide referências finais).
} 
determinada, ou seja, representam o modo como enxergamos e concebemos o mundo social em que habitamos.

É essencial recordar que, para ambos os autores, a palavra, o discurso e/ou a enunciação representam uma ideologia do falante, ou nos termos de Volochínov (2013) a enunciação construída pelo falante representa uma luta de classes. Bakhtin (1995) sustenta que o signo é materializado a partir de uma função ideológica e, posteriormente, discorre sobre a palavra. Para o autor "a palavra, ao contrário, é neutra em relação a qualquer espécie de função ideológica específica. Pode preencher qualquer espécie de função ideológica, estética, científica, moral, religiosa". (BAKHTIN, 1995, p. 37). Nesse sentido, embora o autor utilize o termo "neutro" para referir-se à palavra, fica nítido que a palavra pode preencher qualquer função ideológica, ou seja, a palavra pode ser concebida a partir de diferentes perspectivas ideológicas. E assim, o autor afirma que "a palavra acompanha e comenta todo ato ideológico" (BAKHTIN, 1995, p. 37). Após este breve traçado comparativo entre ambos os autores, concluímos que, nenhuma palavra, nenhum discurso e nenhuma enunciação é construída sem a marca de uma ideologia, que por sua vez, representa o posicionamento e a luta de classes de uma sociedade determinada.

\section{REFLEXÕES SOBRE O MOVIMENTO ESCOLA SEM PARTIDO}

Considerando, pois, que todo discurso é ideológico e que nenhuma palavra ou signo constrói-se sem a presença de um posicionamento ideológico, buscamos discorrer sobre o Escola sem Partido, com o objetivo de refletir sobre a inconsistência teórica deste projeto.

O movimento Escola sem Partido fundado pelo advogado e procurador do Estado de São Paulo, Miguel Nagib, busca propor três soluções para o complexo quadro da educação brasileira. Para ele, é necessário: a) divulgar testemunhos de discentes de todo o Brasil que tenham sido vítimas de doutrinação ideológica; b) Criar Leis que criminalizam o pensamento reflexivo e limitam a liberdade de ensinar; c) Enviar notificações extrajudiciais a fim de que os professores se limitem a ensinar conteúdos sem posicionamentos ideológicos e políticos. 
Como resultado deste movimento, propõem-se seis orientações que deverão ser enviadas para as escolas públicas em forma de cartazes que, por sua vez, deverão ser fixados em todo o ambiente escolar. A seguir, foi reproduzido o cartaz em questão:

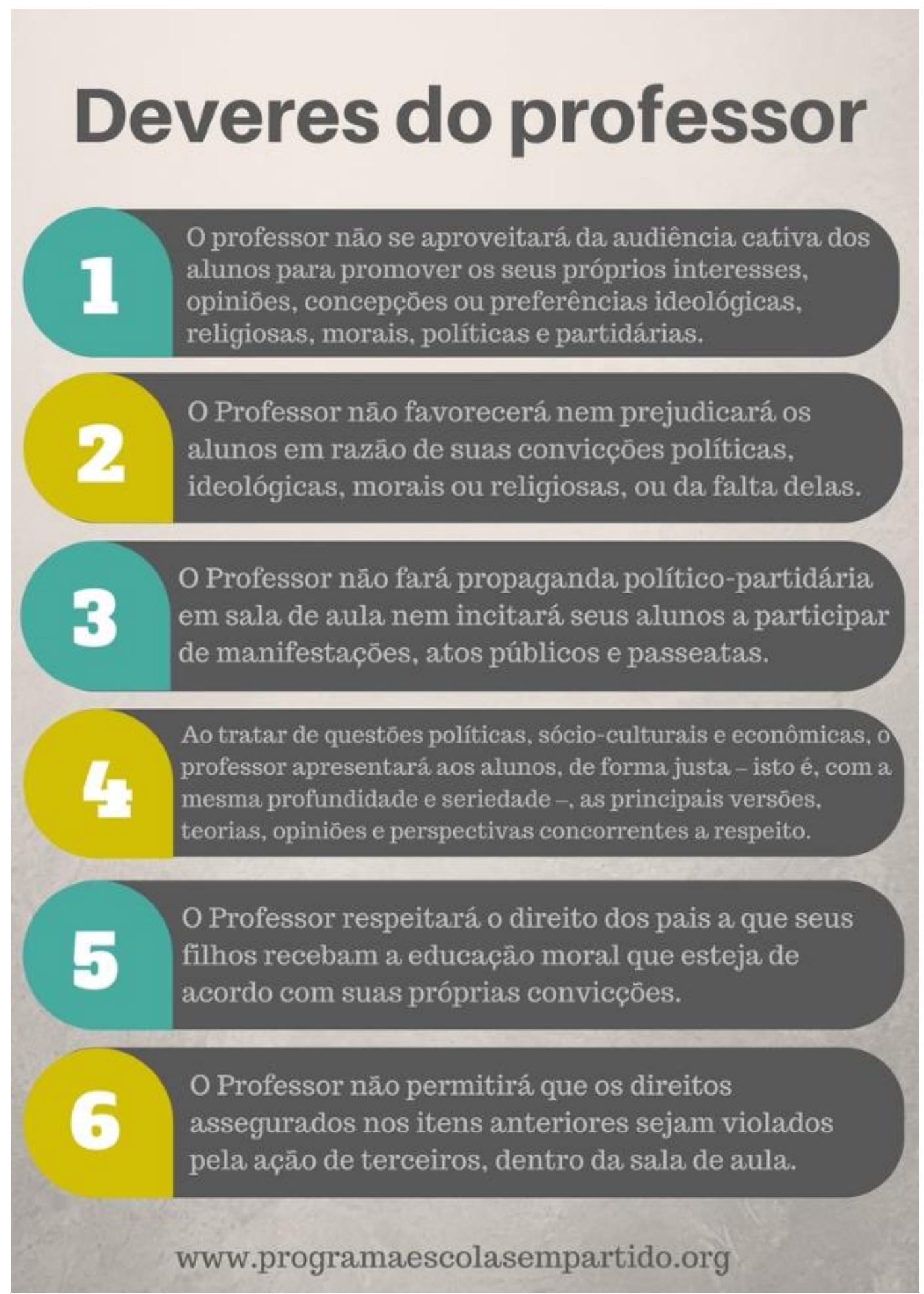

Fonte: www.programaescolasempartido.org 
Para ilustrar a discussão proposta em nosso artigo, analisaremos os pontos 04 e 05 que compõem as orientações do projeto Escola sem Partido para os professores brasileiros. O ponto 04 sugere:

Ao tratar de questões políticas, sócio-culturais e econômicas, o professor apresentará aos alunos, de forma justa - isto é, com a mesma profundidade e serenidade -, as principais versões, teorias, opiniões e perspectivas concorrentes a respeito.

Quadro 02: elaborada pelos autores com base no projeto Escola sem Partido

Este projeto sugere que o professor apresente aos alunos as principais versões, teorias, opiniões e perspectivas sobre determinado assunto abordado em sala de aula. Dito com outras palavras, o projeto propõe que apenas a história oficial seja contada em sala de aula. Em nossa opinião, é fundamental que o professor apresente outras versões, teorias, opiniões e perspectivas sobre assuntos diversos em sala de aula, pois é desta maneira que o pensamento crítico e reflexivo se construirá. Para além disso, ao tratar de questões políticas, o discurso do docente não será neutro, assim como o discurso dos alunos e o próprio discurso do EsP, por isto é relevante considerar as diversas formas de observar e conceber o mundo. O ponto 05 sugere:

professor respeitará o direito dos pais a que seus filhos recebam a educação moral que esteja de acordo com suas próprias convicções.

Quadro 03: elaborada pelos autores com base no projeto Escola sem Partido

Para o movimento Escola sem Partido, o professor deverá abordar os conteúdos que estejam alinhados à educação moral dos pais. Ora, o projeto EsP encontra-se vinculado à setores ultraconservadores da agenda política do Brasil contemporâneo, e nesse sentido, aliar os conteúdos que serão ensinados em sala de aula ao pensamento da família dos alunos, além de uma obnubilação, representa a limitação do pensamento reflexivo e da autonomia didáticopedagógica dos professores brasileiros.

Além disto, como pudemos observar a partir dos textos de Bakhtin (1995) e Volochínov (2003), a palavra possui uma função social e, portanto, o nosso 
discurso encontra-se permeado por nossas ideologias e pelos nossos paradigmas de leitura do mundo. Por isso, pensar na coexistência de uma escola sem ideologias significa considerar o projeto de uma escola sem pensamento crítico e reflexivo.

\section{ALGUMAS PALAVRAS NÃO CONCLUSIVAS}

Neste artigo, revisitamos dois textos fundamentais para os estudos linguísticos e discursivos: Bakhtin (1995) e Volochínov (2013) para discorrer sobre a orientação social e ideológica da palavra. A partir da discussão proposta por estes dois autores, percebemos que o discurso é, em sua essência, carregado por nossas ideologias e pelos nossos paradigmas de leitura do mundo em que vivemos.

Para fins de aplicação analítica, discorremos sobre o Movimento Escola sem Partido, o qual objetiva a promoção de uma escola sem ideologias. A partir da revisão teórica apresentada neste artigo, frisamos que todo discurso é ideológico e carregado de nossas vivências, experiências e expectativas de atuação no mundo em que vivemos.

Por esta razão, ao considerar os estudos de Bakhtin (1995) e Volochínov (2013), apontamos para a incoerência teórica do Movimento Escola sem Partido, frisando três pontos fundamentais: a) Não existe discurso neutro, todo discurso é carregado por nossas experiências e modos de enxergar, agir e conceber 0 mundo; b) O Movimento Escola sem Partido é um projeto político e, portanto, ideológico, pois representa um modo de enxergar a sala de aula; c) Este projeto é nocivo por limitar o pensamento reflexivo e por criminalizar a ação docente e a autonomia dos professores brasileiros.

\section{REFERÊNCIAS}

BAKHTIN, M. Marxismo e filosofia da linguagem: problemas fundamentais do Método Sociológico na Ciência da Linguagem. Tradução de Marina Yaguello. São Paulo: Editora Hucitec, 1995.

COSTA JUNIOR, J. V. L. da. Lembrar para não esquecer: memória, história e ficção em aula de língua espanhola. Dissertação de Mestrado em Linguagem e Ensino: Universidade Federal de Campina Grande, 2017. 
JINKINGS, I; DORIA, K; CLETO, M (org). Por que gritamos golpe? Para entender o impeachment e a crise política do Brasil. São Paulo: Boitempo, 2016.

VOLOCHÍNOV, V. N. A construção da enunciação e outros ensaios. São Carlos: Pedro \& João Editores, 2013. 